\title{
Beyond the point of no return? A comparison of genetic diversity in captive and wild populations of two nearly extinct species of Goodeid fish reveals that one is inbred in the wild
}

\author{
NW Bailey ${ }^{1,3}$, C Macías Garcia ${ }^{2}$ and MG Ritchie ${ }^{1}$ \\ ${ }^{1}$ Department of Environmental and Evolutionary Biology, University of St Andrews, St Andrews, Fife, UK and ${ }^{2}$ Departamento de \\ Ecologia Evolutiva, Instituto de Ecologia, Universidad Nacional Autónoma de México, Coyoacán, Mexico DF, México
}

\begin{abstract}
The relative importance of genetic and non-genetic factors in extinction liability has been extensively debated. Here, we examine the levels of genetic variability at 13 (seven informative) loci in wild and captive populations of two endangered species of Mexican Goodeid fish, Ameca splendens and Zoogoneticus tequila. Allelic diversity was higher in the wild populations, and $\mathrm{F}_{\mathrm{IS}}$ lower. Values of $\theta$ $(=4 \mathrm{Ne} \mu)$ were estimated using a coalescent approach. These implied that the effective population size of all captive populations of $A$. splendens were smaller than that of the wild population; qualitatively similar results were obtained using an analytical method based on within-population gene
\end{abstract}

identity disequilibrium. However, the wild population of $Z$. tequila did not show a significantly greater estimate of $\theta$. We used the Beaumont approach to infer population declines, and found that both species showed clear evidence of a decline in effective population size, although this was stronger and probably occurred over a longer period of time in $Z$. tequila than in $A$. splendens. The decline in $Z$. tequila probably occurred before captive populations were established. We discuss implications for the conservation of critically endangered populations.

Heredity (2007) 98, 360-367; doi:10.1038/sj.hdy.6800947; published online 28 February 2007

Keywords: conservation; genetic diversity; ark populations; inbreeding; fish; effective population size

\section{Introduction}

The relative importance of genetic and non-genetic factors in extinction liability has been extensively debated since Lande's (1988) landmark study suggested that demographic factors, such as disturbance-induced life history changes or habitat destruction, were more important predictors of extinction than inbreeding (Frankham, 2005; O'Grady et al., 2004). A recent metaanalysis by Spielman et al. (2004) has shown that critically endangered species usually have reduced genetic variability relative to non-threatened sister species. This has been interpreted as giving renewed support to the idea that genetic factors are important (deSalle, 2005), although clearly the two (demographic and genetic changes) must be intimately related. Very few studies have succeeded in dissentangling genetic and other causes of extinction (Saccheri et al., 1998).

It seems unambiguous that genetic variability must be important to the restoration of extinct or near-extinct species into the wild. More genetically heterogeneous

Correspondence: Dr C Macías Garcia, Departamento de Ecologia Evolutiva, Instituto de Ecología, Universidad Nacional Autónoma de México, A. P. 70-275. c. p. 07510, Coyoacán, Mexico DF, México.

E-mail: maciasg@servidor.unam.mx

${ }^{3}$ Current address: NW Bailey, Department of Biology, University of California, Riverside, CA 92521, USA.

Received 28 February 2006; revised 25 January 2007; accepted 26 January 2007; published online 28 February 2007 stocks are likely to have a better chance of establishing themselves in an environment, which may be different in some respects to the original environment, although quantitative data on this are lacking. Ark projects should be managed to maintain genetic variability in stocks of endangered species, and considerable effort has been put into this. However, it is likely that stocks of species, which are being maintained for potential reintroduction, will previously have been subject to a level of inbreeding in the natural habitat, either owing to natural expansioncontraction cycles or more recent anthropogenic factors before their maintenance in captivity. The influence of historical bottlenecks on effective population size and genetic variability can usually only be inferred indirectly. Although population bottlenecks must be important in some well-known cases of inbred natural populations (Merola, 1994; Crnokrak and Roff, 1998), other studies imply that even severe historical bottlenecks can sometimes have remarkably little effect on reductions in genetic variation at neutral markers (Groombridge et al., 2000; Nichols et al., 2001) and quantitative genetic variation for fitness traits (Howard, 1993; Saccheri et al., 1996), two measures of genetic depletion that need not be correlated (Britten, 1996; Butlin and Tregenza, 1998).

Goodeid fish have often been reported as extinct or extirpated from the wild (De la Vega-Salazar et al., 2003a). This is a family of North American Cyprinodontid topminnows with a continental distribution in areas of increased geological and historical desertification 
(Webb et al., 2004). One species (Empetrichthys merriami) in the subfamily Empetrichthyinae (consisting of the genera Crenichthys and Empetrichthys, originally found in Nevada, USA) became extinct in the last century, and two are classified as vulnerable (IUCN, 2006). The more numerous and ecologically diversified subfamily, the viviparous Goodeinae, occupies most basins of Central Mexico. Of the 37 recognized species two are reported extinct (Allotoca meeki and A. catarinae, and in addition Characodon garmani was described from a single specimen), one is extirpated from the wild (Skiffia francesae) and two have been found in small natural populations despite being repeatedly reported as extinct (De la VegaSalazar et al., 2003b). Ameca splendens and Zoogoneticus tequila are native to the Teuchitlán River, in the Ameca basin (western Mexico), which has experienced massive changes following the building of a dam in 1955. Captive populations of both species have been kept by zoological institutions and dedicated aquarists, and it was from such populations and museum specimens that $Z$. tequila was described (Webb and Miller, 1998). In 2001, a wild population of Z. tequila was discovered (Figure 1) within a very small spring. This was composed of only a handful of adult fish and a few tens of juveniles (De la Vega-Salazar et al., 2003a,b), and represents an extreme case of vulnerability to extinction. In contrast, relatively large populations of $A$. splendens are found in spa springs (De la Vega-Salazar et al., 2003a) within its historical geographic range. Here, we compare the genetic variability, using microsatellite loci, of wild samples of $Z$. tequila (of adults from springs in the Teuchitlán area and their offspring) and $A$. splendens with samples from aquarists stocks maintained in the UK for up to 30 years.

\section{Materials and methods}

\section{Sampling}

Tail fin clips were taken from four populations of $A$. splendens and three populations of Z. tequila (see Table 1 ). One wild population of $A$. splendens was sampled from its native range in the headwaters of the Teuchitlán river, and samples were also obtained from three captive aquaria populations in the UK. The recently discovered wild population (also in the headwaters of the Teuchitlán river) of $Z$. tequila was also sampled. This is the only known wild sample of $Z$. tequila and appears to have been isolated in an extremely small spring (ca. $4 \mathrm{~m}$ in diameter) for many generations (De La Vega-Salazar et al., 2003a,b). To increase the number of wild alleles sampled without further interference with the population, we included the $F_{1}$ offspring of the original population (it was expected that some females collected from the wild were carrying young from previous matings). Fin clips from a captive population of $Z$. tequila were obtained from Chester Zoo. Both sexes were represented in all populations sampled.

\section{DNA extraction and microsatellite analysis}

Genomic DNA was extracted from ethanol-preserved fin clips using the PureGene protocol (Gentra Systems, Minneapolis, MN, USA). We tested eight microsatellites that had been previously developed from various Goodeid species (Hamill et al., 2007): As2, As5, Ca6, Ca10, Iw193, Iw196, Xc18 and Xc25, and a further five from the literature: Zt1.2, Zt1.3, Zt1.6, Zt1.7 and Zt1.9 (Boto and Doadrio, 2003). Each $15 \mu \mathrm{l}$ PCR reaction contained $0.2 \mathrm{mM}$ each dNTP, $0.20-0.33 \mu \mathrm{M}$ each fluorescently labeled primer (Sigma-Proligo, Proligo, France

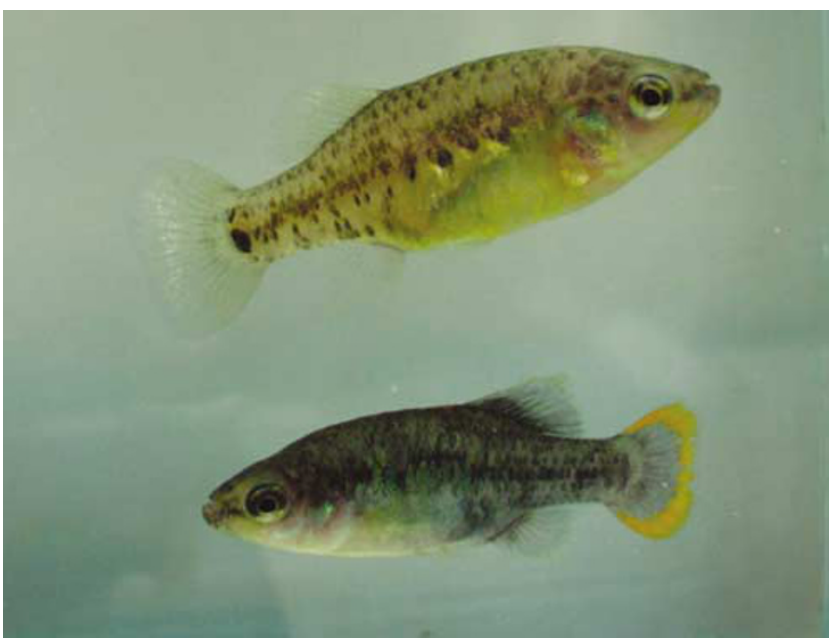

Figure 1 Female (above) and male Z. tequila from the only existing natural population. This was discovered in 2001 in a minute $(4 \times 4 \mathrm{~m}$ in diameter) spring near Teuchitlán, the species was deemed extinct in the wild when it was described in 1998 from museum and aquaria specimens.

Table 1 Populations of A. splendens and Z. tequila sampled

\begin{tabular}{|c|c|c|c|c|}
\hline Population & Number & Wild/captive & Origin & Notes \\
\hline \multicolumn{5}{|l|}{ Z. tequila } \\
\hline Mexico parents & 13 & Wild & Teuchitlán & Parental generation collected from the wild. \\
\hline Mexico offspring & 18 & Wild & Teuchitlán & F1 generation of above, reared in aquaria. \\
\hline Chester zoo & 20 & Captive & Chester zoo & $\begin{array}{l}\text { Zoo population established with individuals from Bolton } \\
\text { museum }(n=4) \text { in } 1995 \text {. }\end{array}$ \\
\hline \multicolumn{5}{|l|}{ A. splendens } \\
\hline Mexico & 20 & Wild & Teuchitlán & \\
\hline St Andrews & 20 & Captive & St Andrews aquarium & $\begin{array}{l}\text { Population established with individuals }(n=16) \text { from London } \\
\text { zoo in 1997. London zoo population originally started in } 1961 \\
\text { using wild individuals }(n=12) \text { from Mexico. }\end{array}$ \\
\hline Chester zoo & 30 & Captive & Chester zoo aquarium & $\begin{array}{l}\text { Population comprised of samples from Bolton museum }(n=7) \text {, } \\
\text { London zoo }(n=5) \text { and Bristol zoo }(n=4) \text { established in } 1995 \text {. }\end{array}$ \\
\hline CZJG & 20 & Captive & Chester zoo aquarium & $\begin{array}{l}\text { Population founded from a } 48 \text {-individual subset of the original } \\
\text { Chester zoo population in } 2001 \text {. }\end{array}$ \\
\hline
\end{tabular}


SAS, Paris, France), $1.5 \mu \mathrm{l} 10 \times \mathrm{NH}_{4}$ reaction buffer, $1.5 \mathrm{mM} \mathrm{MgCl}_{2}, 0.1 \mu \mathrm{l}$ Biotaq DNA polymerase (Bioline UK Ltd., 16 The Edge Business Centre, London, UK) and 10-300 ng DNA template. The PCR profile for all reactions was (1) $5 \mathrm{~min}$ at $94^{\circ} \mathrm{C}$ initial denaturation, (2) $15 \mathrm{~s}$ at $94^{\circ} \mathrm{C}$ denaturation, (3) $10 \mathrm{~s}$ at $60^{\circ} \mathrm{C}$ annealing $\left(55^{\circ} \mathrm{C}\right.$ for $\mathrm{Ca} 10$ and $62^{\circ} \mathrm{C}$ for $\mathrm{Ca}$ ), (4) $1 \mathrm{~min}$ at $72^{\circ} \mathrm{C}$ extension, (5) 39 repeats of steps 2 to 4 and (6) $10 \mathrm{~min}$ at $72^{\circ} \mathrm{C}$ final extension. PCR products were checked on $1.5 \%$ agarose gels. All samples were analyzed on a Beckman Coulter 3000 automated sequencer using 0.5-2.0 $\mu \mathrm{l}$ PCR product plus $0.5-1.0 \mu \mathrm{l} 400$ or $600 \mathrm{bp}$ DNA ladder (BeckmanCoulter (UK) Ltd., Biomedical Research, High Wycombe, Buckinghamshire, England).

Four loci, Ca6, Ca10, Iw193 and Xc25 were monomorphic in both species and were not included in the analysis. Loci Zt1.3 and Zt1.7 did not amplify cleanly despite attempts to re-optimize, so they were also excluded. Locus Zt1.2 was monomorphic in $A$. splendens but polymorphic in $Z$. tequila.

\section{Data analysis}

Hardy-Weinberg equilibrium (HWE) and pairwise population differentiation were tested using Genepop v.3. 4 (Raymond and Rousset, 1995). Within-population measures of mean heterozygosity and mean number of alleles per locus are often presented as proxies for genetic diversity; however, we estimated allelic richness to correct for bias owing to sample size. We also calculated $F_{\text {IS }}$ for each population at each locus, and for each population across all loci combined, to compare levels of inbreeding, and between-population pairwise $F_{S T}$ for each species. Allelic richness and $\mathrm{F}_{\mathrm{IS}}$ were calculated with FSTAT v.2.9.3 (Goudet, 2001), and F ST $_{\text {Tas calcu- }}$ lated with Genepop v.3.4 (Raymond and Rousset, 1995). In all the above analyses, we conservatively treated the parental and the $F_{1}$ samples of $Z$. tequila separately, as these samples may differ, for instance, if we collected a different sample of males from that which fathered the offspring.

We used Migrate v.1.7.3 (Beerli, 1997-2002), part of the package LAMARC, to obtain maximum likelihood estimates of $\mathrm{Ne}$ of each population of $A$. splendens and Z. tequila. Although Migrate is normally used for inferring gene flow between populations, it can be used to draw inferences about single populations (e.g. Kuhner et al., 1998). This uses a coalescent approach coupled with a Monte-Carlo Markov chain technique to estimate $\theta(\theta=4 \mathrm{Ne} \mu$, where $\mathrm{Ne}$ is the effective population size and $\mu$ is the mutation rate) for each population. Migrate uses a random seed to initiate calculations, so replicate estimates of $\theta$ vary. Ten trials were performed for each species and results were compared using one-way ANOVAs. An alternative approach (Vitalis and Couvet, 2001a, b) estimates F (averaged one-locus identity probabilities; a within-population measure of Fst) and Ne for each population based on two locus gene identity probabilities. We used ESTIM (Vitalis and Couvet, 2001c) to generate estimates and confidence intervals (from bootstrapping) of $\mathrm{F}$ and $\mathrm{Ne}$ to compare with the results we obtained using Migrate.

These analyses are useful for estimating contemporary effective population sizes, but are limited because they cannot detect whether a population has been historically declining, expanding or stable. Like Migrate, the programme msvar (Beaumont, 1999) is based on a MCMC technique, but it uses a coalescent approach (assuming a step-wise mutation process) to provide joint likelihood estimates for two additional population demographic parameters of interest to this study. The first is $r$, where $r=N_{0} / N_{1}, N_{0}$ is the current size of the sampled population and $N_{1}$ is the size of a single stable population before decline or expansion. A declining population is expected to give $\log _{10}(r)<0$ and an expanding one $\log _{10}(r)>0$. A stable population size would give $\log _{10}(r)=0$. The second parameter is $t_{\mathrm{f}}$ which is the time (in generations) since the stable ancestral population began to decline or expand $\left(t_{\mathrm{a}}\right)$, scaled by the current population size $\left(N_{0}\right)$, giving $t_{\mathrm{f}}=$ $t_{\mathrm{a}} / N_{0}$. We estimated the parameters of interest for $A$. splendens and $Z$. tequila on the basis of field observations and historical data (De la Vega-Salazar et al., 2003a) and on data from captive-breeding programmes at UNAM, to ensure that they were consistent with the starting parameter bounds used in the program. For $A$. splendens: $N_{0} \approx 4000, N_{1} \approx 10000$ and $t_{\mathrm{a}} \approx 50$. For Z. tequila: $N_{0} \approx 90$, $N_{1} \approx 4500$ and $t_{\mathrm{a}} \approx 50$.

We hypothesized that the wild populations of $A$. splendens and $Z$. tequila have experienced recent population declines and therefore used an exponentially varying population model in the analysis. Only wild populations from each species were included in this analysis, and the data from Mexico Parents and Mexico Offspring in $\mathrm{Z}$. tequila were pooled as a single wild population. As the MCMC chain may require a period of burn-in, we discarded the first 10000 update steps out of $10^{9}$ thinned update steps. Additionally, starting seeds and scale values were varied for three independent runs per species to check for convergence. Our parameter bounds on $\log _{10}(r)$ and $\log _{10}\left(t_{\mathrm{f}}\right)$ were $(-4,-0)$ and $(-2,-1)$, respectively. Increasing the bounds beyond these reduced convergence, we limited the main bounds used to our biologically derived estimates. Similar bounds were used by Beaumont (1999), and encompass a range of parameter values that we considered to be biologically sensible given our estimates of $N_{0}, N_{1}$ and $t_{\mathrm{a}}$ for both species. For example, for $r, N_{0}$ was allowed to be-at the lower bound-four orders of magnitude smaller than $N_{1}$, and-at the upper bound-equal in size to $N_{1}$. We plotted the joint posterior distribution of $\log _{10}(r)$ and $\log _{10}\left(t_{\mathrm{f}}\right)$ following the procedure of Beaumont (1999) and Storz and Beaumont (2002).

\section{Results}

\section{HWE and population differentiation}

We did not detect deviations from HWE in any population of $Z$. tequila at any locus, nor across all loci combined, after Bonferroni correction. This test was applied to detect potential null alleles. In this situation, a Bonferroni correction reduces the stringency of the test, that is, the likelihood that departures from HWE will be detected (Moran, 2003). The use of Bonferroni correction in this case is appropriate to help distinguish loci that are consistently and markedly out of HWE from 'false positives' owing to multiple testing. In A. splendens locus As5 was out of HWE in all populations after Bonferroni correction, indicating the potential presence of null 
alleles, and was therefore discarded from all subsequent analyses. Following this, no $A$. splendens populations showed departures from HWE across the remaining five loci after Bonferroni correction. Allele frequencies are given in Supplementary Tables 1 and 2.

\section{Population differentiation and $\mathrm{F}_{\mathrm{ST}}$}

Pairwise tests of differentiation showed that all Z. tequila populations differed significantly in allele frequency, except Mexico parents and Mexico offspring $\left(\chi_{14}^{2}=11.056, \mathrm{NS}\right)$, and the only $A$. splendens populations that did not differ significantly were Chester Zoo and Chester Zoo Jaguar House $\left(\chi_{8}^{2}=11.086, N S\right)$. Similarly, pairwise $\mathrm{F}_{\mathrm{ST}}$ estimates (Table 2 ) show that the captive populations of $A$. splendens are more similar to each other than they are with the wild population, whereas the wild and captive $Z$. tequila show a substantial degree of divergence. Perhaps unsurprisingly, there are substantial changes in gene frequency between the different stocks.

$\mathrm{F}_{\mathrm{IS}}$

Table 3 shows $F_{\text {IS }}$ values for all populations at each locus, and across all loci (excluding As5 in A. splendens). Captive populations typically show larger values, suggesting that they have experienced inbreeding (heterozygous deficit).

\section{Genetic diversity}

In both $A$. splendens and $Z$. tequila, allelic richness was significantly higher in the wild Mexican populations than in the captive populations (Figure $2 a$ and $b$, respectively). Other diversity indices such as mean

Table 2 Population pairwise $\mathrm{F}_{\mathrm{ST}}$ estimates for (a) A. splendens and (b) Z. tequila Negative $F_{S T}$ values are given as zero.

\begin{tabular}{lccc}
\hline & Mexico & St Andrews & Chester zoo \\
\hline (a) & & & \\
St Andrews & 0.2121 & & \\
Chester zoo & 0.3125 & 0.1725 & \\
CZJG & 0.2822 & 0.1493 & 0.0297 \\
& & & \\
(b) & Mexico parents & Mexico offspring & \\
& 0.0000 & & \\
Mexico offspring & 0.5260 & 0.4915 & \\
Chester zoo & & & \\
\hline
\end{tabular}

heterozygosity, mean number of alleles per locus and total number of alleles per locus showed similar patterns. Averaged single-locus gene identities (F) show the same pattern (Table 4)

\section{Theta $(\theta)$ estimates}

In $A$. splendens, mean $\theta$ across 10 trials was significantly higher in the wild Mexican population (by a factor of four) than in the captive populations (one-way ANOVA: $\mathrm{F}_{3,36}=224.51, P<0.001$, Tukey's comparison significant

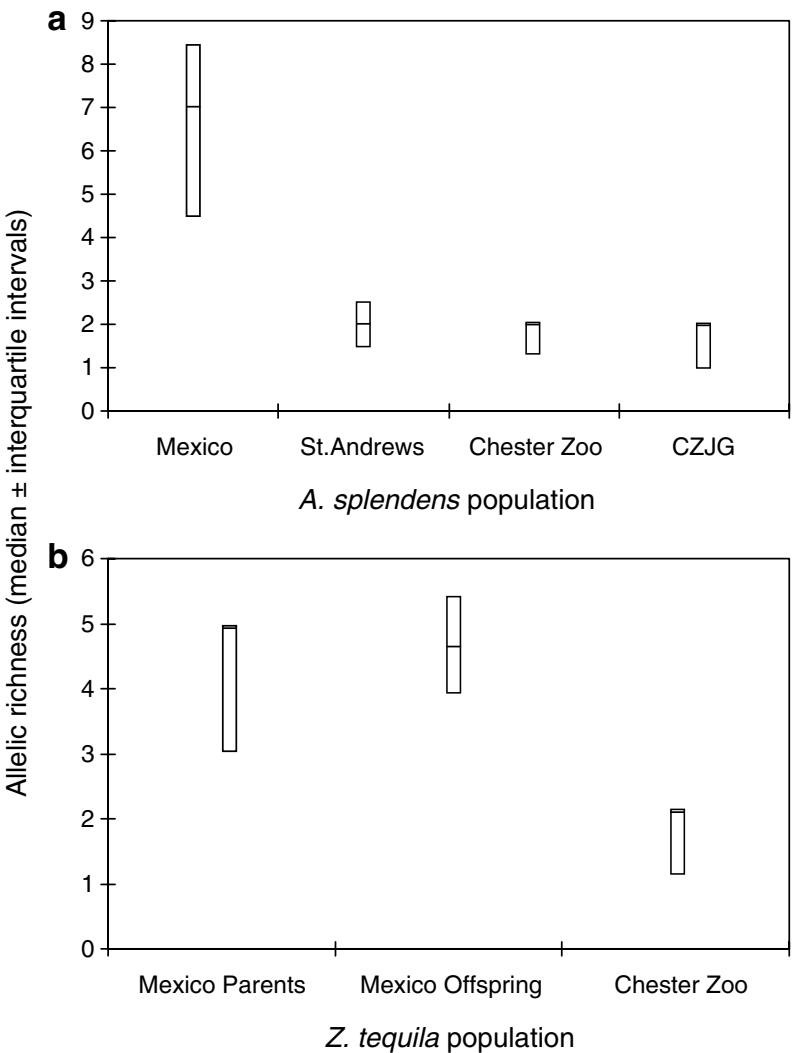

Figure 2 Wild Mexican populations show greater allelic richness in both (a) A. splendens (Kruskal-Wallis: $H_{3,16}=9.66, P<0.02$ ) and (b) Z. tequila (Kruskal-Wallis: $H_{2,18}=12.69, P=0.002$ ). Median values and the first and third inter-quartile ranges are plotted.

Table $3 \mathrm{~F}_{\mathrm{IS}}$ values for each population (and locus) of $A$. splendens and Z. tequila, and $\theta$ values per population generated using Migrate

\begin{tabular}{|c|c|c|c|c|c|c|c|}
\hline \multirow[t]{3}{*}{ Locus } & \multicolumn{3}{|c|}{ Z. tequila } & \multicolumn{4}{|c|}{ A. splendens } \\
\hline & \multicolumn{2}{|c|}{ Mexico } & \multirow[b]{2}{*}{ Chester zoo } & \multirow[b]{2}{*}{ Mexico } & \multirow[b]{2}{*}{ St Andrews } & \multirow[b]{2}{*}{ Chester zoo } & \multirow[b]{2}{*}{ CZJG } \\
\hline & Parents & Offspring & & & & & \\
\hline As2 & -0.114 & 0.022 & -0.192 & -0.178 & 0.016 & 0.039 & 0.587 \\
\hline Iw196 & -0.059 & -0.162 & NA & 0.236 & 0.163 & 0.016 & 0.191 \\
\hline Xc18 & 0.27 & -0.146 & -0.029 & -0.002 & 0.706 & 0 & NA \\
\hline Zt1.6 & -0.3 & -0.311 & 0.333 & -0.086 & NA & NA & NA \\
\hline Zt1.9 & 0.009 & -0.064 & 0.294 & -0.074 & 0.227 & 0.133 & -0.393 \\
\hline $\mathrm{Zt} 1.2$ & 0.008 & -0.136 & NA & & & & \\
\hline As5 & 0.063 & -0.483 & 0.234 & & & & \\
\hline All loci & -0.014 & -0.164 & 0.125 & -0.019 & 0.282 & 0.054 & 0.081 \\
\hline$\theta$ & 0.66 & 0.68 & 0.82 & 1.95 & 0.49 & 0.53 & 0.47 \\
\hline
\end{tabular}

Zt1.2 was not analyzed in A. splendens because it is monomorphic in this species; 'na' indicates that a population was monomorphic at that locus. As5 was discarded from all analyses involving A. splendens because it was out of HWE in all populations. $\theta 95 \% \mathrm{CI}= \pm 0.102702$ (Z. tequila) and $95 \% \mathrm{CI}= \pm 0.09495$ (A. splendens) using pooled s.d. from all populations within a species. 
Table 4 Estimates (and 95\% confidence intervals generated by bootstrapping) obtained using ESTIM for F and Ne (effective population size) in both species. Ne estimates are given for an upper and lower range of mutation rates $(\mu)$

\begin{tabular}{|c|c|c|c|c|c|c|}
\hline & \multirow[t]{2}{*}{$F$} & \multirow[t]{2}{*}{$95 \%$ CI for $F$} & \multicolumn{2}{|c|}{$\mu=1 \times 10^{-2}$} & \multicolumn{2}{|c|}{$\mu=1 \times 10^{-4}$} \\
\hline & & & $\mathrm{Ne}$ & $95 \% \mathrm{CI}$ for $\mathrm{Ne}$ & $\mathrm{Ne}$ & $95 \% \mathrm{CI}$ for $\mathrm{Ne}$ \\
\hline \multicolumn{7}{|l|}{ A. splendens } \\
\hline St Andrews & 0.205 & {$[0.174,0.240]$} & 3.16 & {$[0,16.43]$} & 3.43 & {$[0,20.13]$} \\
\hline Mexico & -0.371 & {$[-0.443,-0.311]$} & $\infty$ & {$[\infty, \infty]$} & $\infty$ & {$[\infty, \infty]$} \\
\hline Chester zoo & 0.483 & {$[0.373,0.605]$} & $\infty$ & {$[7.80, \infty]$} & $\infty$ & {$[15.72, \infty]$} \\
\hline CZJH & 0.445 & {$[0.321,0.589]$} & $\infty$ & {$[\infty, \infty]$} & $\infty$ & {$[\infty, \infty]$} \\
\hline \multicolumn{7}{|l|}{ Z. tequila } \\
\hline Mexico parents & 0.204 & {$[0.142,0.275]$} & 18.35 & {$[5.27,244.53]$} & 21.83 & {$[5.68,1342.676]$} \\
\hline Mexico offspring & 0.179 & {$[0.133,0.227]$} & 11.10 & {$[3.74,28.77]$} & 12.39 & {$[4.02,38.76]$} \\
\hline Chester zoo & 0.718 & {$[0.651,0.785]$} & 0 & {$[0, \infty]$} & 19.90 & {$[2.74, \infty]$} \\
\hline
\end{tabular}

at 3.81). However, in Z. tequila, the mean estimates of $\theta$ of the wild populations were about $20 \%$ smaller than that obtained for the captive population, although the difference was not significant (one-way ANOVA: $\mathrm{F}_{2,27}=2.85, P=0.075$; Table 3).

\section{Comparison of $\mathrm{Ne}$ over a range of mutation rates $(\mu)$}

The central aim of our analysis was to draw a comparison of genetic variation between wild and captive populations; however, these data do allow an inference of relative effective population size. Any such estimate relies on knowledge of the mutation rate $(\mu)$ of the genetic markers used in the analysis. The analysis performed in Migrate assumes a constant-and equalmutation rate across all microsatellite loci, but estimates of microsatellite mutation rates range widely depending on both the organism and the locus examined (Weber and Wong, 1993; Schug et al., 1998; DeWoody and Avise, 2000; Schlötterer, 2000). DeWoody and Avise (2000) used microsatellite mutation rates between $10^{-2}$ and $10^{-4}$ (based on studies in humans and Drosophila melanogaster) to estimate $\mathrm{Ne}$ in freshwater fish. As with the $\theta$ estimates, average $\mathrm{Ne}$ of the wild $A$. splendens population is highest, varying from 19 to 4867 within the range of mutation rates from $10^{-2}$ to $10^{-4}$. Average $\mathrm{Ne}$ of both wild and captive $Z$. tequila populations are in the same order of magnitude as that of the captive $A$. splendens, in the lowest instance (CZJH) only reaching 1164 for a mutation rate of $10^{-4}$. Values of $\mathrm{Ne}$ calculated using ESTIM are consistently smaller (Table 4) but showed similar trends. ESTIM produced more cases of undetermined $\mathrm{Ne}$ $(\mathrm{Ne}=\infty)$ when $n_{\mathrm{s}}$ (the two-locus averaged identity disequilibrium within subsamples relative to the total sample) was negative. Nevertheless, similar conclusions can be drawn from the use of these different methodological approaches; both populations of $Z$. tequila appear to be genetically very small, and are comparable to the captive populations of $A$. splendens.

\section{Detecting population decline}

Both $A$. splendens and $Z$. tequila show evidence of exponential population decline (Figure 3), although the evidence in Z . tequila is stronger. The more severe decline in Z. tequila may have occurred over a longer period of time, as the $10 \%$ highest posterior density (HPD) contour for $t_{\mathrm{f}}$ is about one and a half orders of magnitude greater

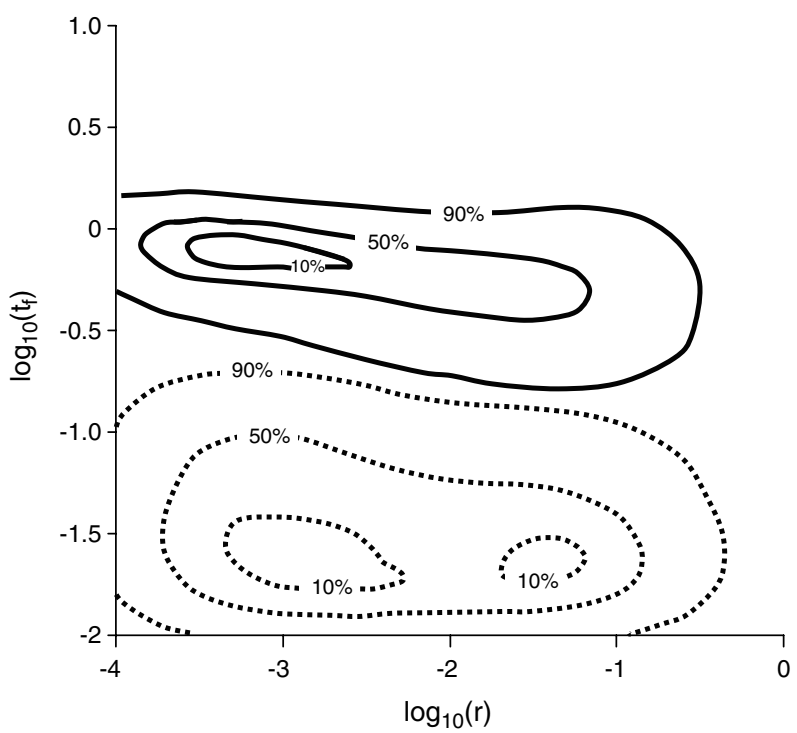

Figure 3 Joint posterior distribution of $\log _{10}(r)$ and $\log _{10}\left(t_{\mathrm{f}}\right)$ for wild A. splendens population (dotted line) and wild Z. tequila population (solid line) showing 10, 50 and 90\% HPD contours.

than that of $A$. splendens, indicating that the time since decline for $A$. splendens may have been much shorter. Contours for the HPD limits indicate the region within which the probability of the parameter values is a critical value (Beaumont, 1999). For example, the 90\% HPD contour gives the region within which the densest $90 \%$ of sample points lie, and can provide a measure of confidence in the parameter estimation. Convergence (i.e. consistency in the $90 \%$ HPD contours) occurred in both species over multiple long runs of $10^{9}$ thinned update steps using variable starting seeds and parameter scale values. However, the presence of multiple $10 \%$ HPD peaks in each run of $A$. splendens suggests that convergence in this species may be weaker (see Figure 3 ). The $90 \%$ HPD limits on $\log _{10}(r)$ never cross zero for either $A$. splendens or $Z$. tequila in any of the runs, however, which provides consistent support for exponential population decline in both species.

The stronger convergence in $Z$. tequila, that is, the consistency of the $10 \%$ HPD contour across several runs, suggests that the population size of this species before decline was roughly three orders of magnitude larger 
than the present size. Convergence of $10 \%$ HPD contours in A. splendens is weaker. However, if we consider a range of values corresponding to the two peaks in Figure 3 (which were also consistent across runs), a predecline population could have been between 1.5 and three orders of magnitude larger than the present size.

\section{Discussion}

We have found that a wild population of $A$. splendens is much more genetically diverse than stocks, which have been maintained in captivity for up to 10 years. Its effective population size is more than an order of magnitude greater. However, Z. tequila (endemic to the basin of the small Teuchitlán River) provides a striking contrast. Although a wild population contains more alleles than the captive stock, the calculated $\theta$, an index of effective population size is not significantly greater than that of the captive population. The allelic richness of the wild Z. tequila population is lower (around half) than that of wild A. splendens, and across the family Goodeidae as a whole allelic richness is more like that seen in wild $A$. splendens or greater (Hamill et al., 2007). The variability of allele lengths in $\mathrm{Z}$. tequila suggests that the population decline has been stronger and over a longer period than that in A. splendens, which is consistent with their current conservation status. Our interpretation is that the wild $Z$. tequila population, which is the only known extant population (De la Vega-Salazar et al., 2003a,b), shows signs of declining genetic variability over its probable ancestral levels of diversity. A previous report using fewer markers (Boto and Doadrio, 2003) found that $Z$. tequila had a lower heterozygosity than its common and widespread sister species (Z. quitzeoensis).

Our results appear to be consistent with the hypothesis of Spielman et al. (2004) that inbreeding drives extinction. However, interspecific comparisons fail to disentangle the potentially confounding problem of causality (i.e. whether species go extinct because they become inbred or whether species that are vulnerable to extinction are also, for unrelated reasons, prone to have reduced genetic variability), so such evidence is far from conclusive (Frankham, 2005). Lande (1988) argued that demographic factors are paramount in driving extinction, a view supported by some recent reports of substantial demographic recovery of genetically impoverished populations (e.g. the Oryx, Oryx leucoryx; Mésochina et al. (2003); the elephant seal, Mirounga angustirostrus; Hoelzel et al., 1993), or others where population reduction was not clearly associated with a decrease in genetic variability (the Mauritius kestrel, Falco punctatus; Groombridge et al., 2000). However, Saccheri et al. (1998) found that extinction risk in butterflies was better predicted by genetic than ecological factors. It is even uncertain whether small population size and isolation necessarily lead to the loss of genetic diversity (e.g. the Mauritius kestrel, Falco punctatus; Groombridge et al., 2000 and the butterfly Erebia epiphron silesiana; Schmitt et al., 2005). It appears that sometimes, if the impact of anthropogenic factors is severe, populations may go extinct without undergoing genetic bottlenecks. However, seemingly genetically impoverished populations can thrive, perhaps because inbreeding measured from neutral markers is often only loosely (if at all) related to quantitative fitness-related traits
Inbreeding in ark and relict populations

NW Bailey et al

(Britten, 1996; Butlin and Tregenza, 1998; Slate et al., 2004).

Although it is extremely unlikely that all species become extinct due to inbreeding, the loss of genetic diversity can be a risk factor ( $\mathrm{O}^{\prime}$ Grady et al., 2004), and maintaining diversity is a major aim of ark projects. Estimates of the effect of inbreeding on fitness based on experimental manipulations (for instance, the superiority of cross- over self-pollinated Silene douglasii; Kephart, 2004) may not be applicable to naturally endangered species, which might have an evolutionary history of coping with low heterozygosity. Indeed, outcrossing may be detrimental for naturally inbred populations (e.g. outcrossed inbred males produce malformed tadpoles in Rana temporaria; Sagvik et al., 2004), particularly when they are outcrossed with captive populations, as demonstrated by the loss, rather than gain of genetic diversity in the Western mosquito fish, Gambusia affinis following the release of fish from captive stocks (Stockwell et al., 1996). There is also evidence from captive studies that establishing populations from multiple stocks can lead to outbreeding depression in the related G. holbrooki (Leberg, 1993).

There are no estimates of demographic parameters such as mean litter size, age at first reproduction or growth rate for either $A$. splendens or $Z$. tequila, yet recently established stocks derived from these wild parents are currently thriving in outdoor ponds. Thus, there is no obvious evidence of inbreeding depression, perhaps because deleterious alleles have been purged. We propose that, evidence of low $\theta$ values for $Z$. tequila notwithstanding, the viability of wild stocks should not be compromised by attempts to increase their genetic diversity in the absence of evidence of inbreeding depression. In the case of $A$. splendens, introducing fish from captive stocks cannot substantially increase genetic diversity, and may promote the spread of deleterious alleles adapted to captivity (Lynch and O'Hely, 2001). Indeed, there is evidence (Kelley et al., 2006) that captivity has led to a higher, potentially maladaptive aggressive behavior in this species. The case of $Z$. tequila is more complex. Both captive and wild populations have private alleles and thus can potentially enrich the genetic diversity of each other. However, the wild population has survived in isolation, at small numbers, for at least 15 years (De la Vega-Salazar et al., 2003b), which is probably long enough to have undergone some level of local adaptation. In this case, we face a poignant trade-off: to risk breaking down a locally adapted genome (and one purged of deleterious alleles) by introducing alleles adapted to captivity, or to risk local extinction due to stochastic environmental changes to which this genetically impoverished population cannot adapt.

The solution to such trade-offs partly depends upon our definition of a population. If we accept that the small deme of $Z$. tequila still holding out at a tiny spring in Teuchitlán is unique, we would be endorsing the value of its genetic identity. This would preclude rescue attempts such as that conducted with the population of adders (Vipera berus) at Smygehuk, Sweden (Madsen et al., 1999), where population decline prompted an exercise in genetic rescue that led not only to a demographic recovery, but also produced a population that is genotypically different from the original one. If the 
objective was to save the unique population of adders at Smygehuk, the attempt failed, but if the aim was to keep alive a population of adders at Smygehuk (with some of its original genes), it was an unqualified success. We think that the unique population of $Z$. tequila at Teuchitlán is beyond the point of no return unless we manage to recover a substantial portion of its original habitat and thus allow it to increase its numbers. But we can preserve some of its genes, we can combine them with those of the captive stocks and we can design management programes that minimize the negative impact of captivity by incorporating selective agents as similar as possible to those experienced in the wild. But, in the long run, husbandry leads to domestication. Skiffia francesae, a relative of these species, is completely extinct in the wild and we can detect no allelic variation at these loci in captive populations (personal observation; see also Boto and Doadrio, 2003). Ultimately, we must restore the environment to maintain critically endangered populations of species. In the mean time, efforts should be made to understand the relationship between quantitative fitness traits and inbreeding at neutral loci, so as to be able to assess the potential for survival of small populations when released in recovered environments.

\section{Acknowledgements}

We thank Gordon Reid, Mike Crumpler and Stephanie Sanderson (Chester Zoo), the staff at the St Andrews Sea Life Centre, and Marina de la Vega-Salzar, Edgar Avila Luna and Mylene Mariette (UNAM) for providing samples. Shane A Webb, Emma Smart, Tanya Hamill and Ruth Hamill helped with the development of microsatellites, J Graves and Anne E Magurran kindly read and commented on the manuscript, and Mark A Beaumont and others advised on the analyses. We also thank Renaud Vitalis for help using ESTIM, and two anonymous reviewers for their constructive criticism. This research adhered to the Association for the Study of Animal Behaviour/Animal Behavior Society Guidelines for the Use of Animals in Research.

\section{References}

Beaumont MA (1999). Detecting population expansion and decline using microsatellites. Genetics 153: 2013-2029.

Beerli P (1997-2002). Migrate: documentation and program, part of LAMARC. Version 1.7.3. Distributed over the internet, http:/ / evolution.genetics.washington.edu/lamarc.html.

Britten HB (1996). Meta-analyses of the association between multilocus heterozygosity and fitness. Evolution 50: 2158-2164.

Butlin RK, Tregenza T (1998). Levels of genetic polymorphism: marker loci versus quantitative traits. Philos Trans $R$ Soc London Ser B 353: 187-198.

Boto L, Doadrio I (2003). Polymorphic microsatellites in two different species of the genus Zoogoneticus Meek, 1902 (Goodeidae, Actynopterygii). Mol Ecol Notes 3: 70-72 (doi: 10.1046/j.1471-8286.2003.00353.x).

Crnokrak P, Roff DA (1998). Inbreeding depression in the wild. Heredity 83: 260-270.

De la Vega-Salazar MY, Avila-Luna E, Macías-Garcia C (2003a). Ecological evaluation of local extinction: the case of two genera of endemic mexican fish, Zoogoneticus and Skiffia. Biodiversity Conserv 12: 2043-2056.

De la Vega-Salazar MY, Avila-Luna EG, Macías-Garcia C (2003b). Threatened fishes of the word: Zoogoneticus tequila
(Webb and Miller, 1998) (Goodeidae). Environ Biol Fishes 68: 14.

DeSalle R (2005). Conservation genetics - genetics at the brink of extinction. Heredity 94: 386-387.

DeWoody JA, Avise JC (2000). Microsatellite variation in marine, freshwater and anadromous fishes compared with other animals. J Fish Biol 56: 461-473.

Frankham R (2005). Genetics and extinction. Biol Conserv 126: 131-140.

Goudet J (2001). FSTAT, a program to estimate and test gene diversities and fixation indices (version 2.9.3). Available from http:/ / www.unil.ch/izea/softwares/fstat.

Groombridge JJ, Jones CG, Bruford MW, Nichols RA (2000). Ghost alleles of the Mauritius kestrel. Nature 403: 616.

Hamill RM, Webb SA, Macías Garcia C, Graves JA, Magurran AE, Ritchie MG (2007). Comparison of genetic diversity at microsatellite loci in near-extinct and non-endangered species of Mexican goodeine fishes and prediction of crossamplification within the family. J Fish Biol 70 (Suppl A): $16-32$.

Hoelzel AR, Halley J, O'Brien SJ, Campagna C, Arnbom T, LeBoeuf B et al. (1993). Elephant seal genetic variation and the use of simulation models to investigate historical population bottlenecks. J Hered 84: 443-449.

Howard D (1993). Small populations, inbreeding and speciation. In: Thornhill NW (ed). The Natural History of Inbreeding and Outbreeding: Theoretical and Empirical Perspectives. University of Chicago Press: Chicago. pp 118-142.

IUCN (2006). 2006 IUCN Red List of Threatened Species. http:/ / www.iucnredlist.org.

Kelley J, Magurran AE, Macías Garcia C (2006). Captive breeding promotes aggression in an endangered Mexican fish. Biol Conserv 133: 169-177.

Kephart SR (2004). Inbreeding and reintroduction: progeny success in rare Silene populations of varied density. Conserv Genet 5: 49-61.

Kuhner MK, Yamato J, Felsenstein J (1998). Maximum likelihood estimation of population growth rates based on the coalescent. Genetics 149: 429-434.

Lande R (1988). Genetics and demography in biological conservation. Science 241: 1455-1460.

Leberg PL (1993). Strategies for population reintroduction: effects of genetic variability on population growth and size. Conserv Biol 7: 194-199.

Lynch M, O'Hely M (2001). Captive breeding and the genetic fitness of natural populations. Conserv Genet 2: 363-378.

Madsen T, Shine R, Olsson M, Wittzell H (1999). Restoration of an inbred adder population. Nature 402: 34-35.

Merola M (1994). A reassessment of homozygosity and the case for inbreeding depression in the cheetah (Acinonyx jubatus): implications for conservation. Conserv Biol 8: 961-971.

Mésochina P, Bedin E, Ostrowski S (2003). Reintroducing antelopes into arid areas: lessons learnt from the oryx in Saudi Arabia. C R Biol 326: S158-S165.

Moran MD (2003). Arguments for rejecting the sequential Bonferroni in ecological studies. OIKOS 100: 403-405.

Nichols RA, Bruford MW, Groombridge JJ (2001). Sustaining genetic variation in a small population: evidence from the Mauritius kestrel. Mol Ecol 10: 593-602.

O'Grady JJ, Reed DH, Brook BW, Frankham R (2004). What are the best correlates of predicted extinction risk? Biol Conserv 118: 513-520.

Raymond M, Rousset F (1995). GENEPOP (version 1.2): population genetics software for exact tests and ecumenicism. J Hered 86: 248-249.

Saccheri I, Kuussaari M, Kankare M, Vikman P, Fortelius W, Hanski I (1998). Inbreeding and extinction in a butterfly metapopulation. Nature 392: 491-494.

Saccheri IJ, Barkefield PM, Nichols RA (1996). Severe inbreeding depression and rapid fitness rebound in the butterfly Bicyclus anynana (Satyridae). Evolution 50: 2000-2013. 
Sagvik J, Uller T, Olsson M (2004). Outbreeding depression in the common frog, Rana temporaria. Conserv Genet 6: 205-211.

Schlötterer C (2000). Evolutionary dynamics of microsatellite DNA. Chromosoma 109: 365-371.

Schmitt T, Cizek O, Konvicka M (2005). Genetics of a butterfly relocation: large, small and introduced populations of the mountain endemic Erebia epiphron silesiana. Biol Conserv 123: 11-18 (doi:10.1016/j.biocon.2004.09.018).

Schug MD, Hutter CM, Noor MAF, Aquadro CF (1998). Mutation and evolution of microsatellites in Drosophila melanogaster. Genetica 102-103: 359-367. Sp. Iss.

Slate J, David P, Dodds KG, Veenvliet BA, Glass BC, Broad TE et al. (2004). Understanding the relationship between the inbreeding coefficient and multilocus heterozygosity: theoretical expectations and empirical data. Heredity 93: 255-265.

Spielman D, Brook BW, Frankham R (2004). Most species are not driven to extinction before genetic factors impact them. Proc Natl Acad Sci USA 101: 15261-15264 (doi_10.1073_pnas. 0403809101).

Stockwell CA, Mulvey M, Vinyard GL (1996). Translocations and the preservation of allelic diversity. Conserv Biol 10: 1133-1141.
Storz JF, Beaumont MA (2002). Testing for genetic evidence of population expansion and contraction: an empirical analysis of microsatellite DNA variation using a hierarchical Bayesian model. Evolution 56: 154-166.

Vitalis R, Couvet D (2001a). Estimation of effective population size and migration rate from one- and two-locus identity measures. Genetics 157: 911-925.

Vitalis R, Couvet D (2001b). Two-locus identity probabilities and identity disequilibrium in a partially sefling subdivided population. Genet Res Camb 77: 67-81.

Vitalis R, Couvet D (2001c). ESTIM 1.0: a computer program to infer population parameters from one- and two-locus identity probabilities. Mol Ecol Notes 1: 354-356.

Webb SA, Graves JA, Macías-Garcia C, Magurran AE, Foighil DO, Ritchie MG (2004). Molecular phylogeny of the livebearing Goodeidae (Cyprinodontiformes). Mol Phylogenet Evol 30: 527-544.

Webb SA, Miller RR (1998). Zoogoneticus tequila, a new Goodeid fish (Cyprinodontiformes) from the Ameca drainage of Mexico, and a rediagnosis of the genus. Occ Pap Mus Zool Univ Mich 725: 1-23.

Weber JL, Wong C (1993). Mutation of human short tandem repeats. Hum Mol Genet 2: 1123-1128.

Supplementary Information accompanies the paper on Heredity website (http://www.nature.com/hdy) 